\title{
The cold chain of chilled products under supervision in France
}

\author{
Derens E. , Palagos B. , Guilpart J. \\ Refrigeration processes engineering research unit \\ Cemagref, Parc de Tourvoie, BP 44 \\ F92163 Antony Cedex \\ Corresponding author: evelyne.derens@cemagref.fr \\ Tel : + 33140966020
}

\begin{abstract}
In the food safety domain, the respect of the cold chain is of prime importance. The present paper presents an original method to monitor the food cold chain of everyday refrigerated food products sold in self service counters of supermarkets and hypermarkets in France. The proposed method consists in dissimulating a small temperature recorder inside the food product at the end of the production line and to send this product, equipped with the concealed device yet undistinguishable from any other, throughout the supply chains. At the end of the cold chain, the consumer who discovers the recorder is invited to send it back to the laboratory.

Three types of products were chosen depending on their recommended conservation temperature, their shape and the logistic circuit they were likely to follow. 480 recorders have sent. A return rate of $65 \%$ allows the observation of the complete thermal history observed in 314 food products, representing a sum of more than 3800 recording days.

The results are presented in a qualitative form (degrees of compliance / non compliance of the recommended temperature) as well as a quantitative form (average temperature and residence time of the products in the different links of the cold chain) over the entire cold chain, and for each link of the cold chain. The results indicate that $3 / 4$ of the food product are conserved in good / very good temperature conditions, and that $3 \%$ of the observations dramatically exceed the recommendations, especially at the last stages of the cold chain.
\end{abstract}

Key words: food cold chain, survey, temperature, residence time, statistics

\section{INTRODUCTION}

In matter of food safety, a better control of the cold chain is of prime importance and is expected from the consumer. Today, it is well known that some of the links of this cold chain are especially weak, and some studies particularly focus on this point [ 1 ], [ 2 ], [ 3 ], [ 4]. Nevertheless, the real and complete thermal history of a refrigerated food product, i.e. from the end of the production line down to the consumer's plate remains badly known. Indeed, this thermal history depends on many parameters, among which the logistic circuits undertaken by the product and the temperature level encountered at each link of this logistic circuit. In consequence, a better knowledge of the "quality" of the food cold chain requires a fine and statistical study of the possible arrangements of the different links of the logistic circuit (e.g. the number of intermediaries the product went through). It also requires a better knowledge of 
the residence time of the food in each of these links. And to end, it requires the measurement of the temperature level encountered in these different links of the cold chain.

The present study focus on the refrigerated industrial fresh or prepared every day food products sold in self-service counters of super and hypermarkets. This choice can be explained by the fact that this type of product constitutes the main part of the food we consume: the best estimates result in saying that $50 \%$ of yoghourts and $18 \%$ of meat products consumed in France are sold through these channels. It can also be explained by the fact that this type of refrigerated food product can be regarded as the most susceptible to risk on the food safety level.

In consequence, the results presented here should not be extended to the cold chain of other products or to other logistic circuits, such as for example craft products distributed on open markets.

\section{MATERIAL AND METHOD}

\section{General principle}

In order to acquire a statistical knowledge of these three main parameters (sequencing the logistical circuit, residence time and temperature in each link of the cold chain), we proposed to dissimulate a small temperature recorder (cf. Figure 1) inside the product in a way that the instrumented product was unrecognisable from the other products. This temperature recorder was installed at the end of the production line and then, it was packed and dispatched with other "normal" products. In this way, the instrumented product underwent exactly the same thermal history as all other ones.

\section{Retained products and instrumentation}

Three types of products were chosen according to their conservation temperature, their size and shapes and the variety of logistic circuits they could follow (direct delivery to the store, or with one or several intermediaries). Table 1 indicates the number of temperature recorders in dairy products (yoghurt), in prepared meat products and in packed meat products. It indicates that 480 recorders were sent.

In practice, the recorder was placed at the interface between product and packing, so that the recorded temperature corresponds to an intermediate value between product and air temperature. Nevertheless, the thermal inertia of both the recorder and the product, coupled with the thermal resistance of the packing can induce to think that the recorded temperature is closer to that of the product than that of the air. This assumption was confirmed by experiments led in our laboratory where slight differences $\left(0.1^{\circ} \mathrm{C}\right)$ between the recorded temperature and the skin temperature of the product were observed (cf. Figure 2) 


\section{Return rate of the recording devices.}

The main challenge we had to face was to recover the temperature recorder discovered by the consumer when he found it when opening the pack. For this, an explanation booklet inserted in the packing indicates the purpose of the study, and invited the consumer to return the sensor (in a prepaid envelop) against a reward of 25 euros.

This amount of 25 euros was fixed following a literature review, allowing us to relate the response rate to a survey to the motivation of the consumer. The results of this preliminary study made it possible to estimate that a return rate of $70 \%$ could be hoped. Let us note that this study was accompanied by targeted media publicity (press releases and television news). The return rate we obtained is indicated in Table 1. It indicates that our forecast was very close to the obtained values.

\section{Geographical representativity of the study.}

The Figure 3 indicates the localisation of the places where the consumer discovers the recorders in their food. It shows that the French territory was well covered.

\section{Sequencing of the records.}

A typical record is presented Figure 4. The treatment and the sequencing of these records is an essential stage preliminary to the statistical treatment of the data.

This sequencing was based on the logistic information delivered by the manufacturer who is able to precisely know where and when is a product under his responsibility: one can see here a positive consequence of the traceability concept. Once the product arrives at retail level, the regular temperature fluctuations related to the frost and defrost cycle of the display cabinet helped to detect this link. An autocorrelation analysis of the signal was also used for this purpose [ 6 ]. Then the important temperature rise during the transport between the retailer and the domestic refrigerator was quite easy to detect, allowing the sequencing of this end part of the cold chain. An example of sequencing is presented Figure 4.

\section{Exploitation of the records}

The exploitation of the records was made at three levels:

(i) considering the entire cold chain, i.e. from the end of the production line down to the consumer's refrigerator,

(ii) sharing the record in two parts, the first one being the "professional" part of the cold chain (storage, transport and retail), and the second one being the "domestic" part of the cold chain where the management of the cold chain is between the hands of non-professionals,

(iii) and at least, links per links of the cold chain. 
6 different links have been retained: (1) the refrigerated transport, (2) the warehouse , (3) the distribution platform, (4) the display cabinet, (5) the domestic transport, and (6) the household refrigerator.

Qualitative approach

A qualitative evaluation of the cold chain requires the establishment of a reference scale, applicable both to the dairy products (recommended conservation temperature: $+6^{\circ} \mathrm{C}$ ) and to the meat products (recommended temperature: $+4^{\circ} \mathrm{C}$ ). We propose to define a reference scale of 6 classes framing the recommended temperature value as described in Figure 5.

- Class $\mathrm{H}$ corresponds to negative temperature, involving a texture and structure degradation of the product, especially for dairy products,

- $\quad$ Classes A and B can be regarded as good regarding the safety of food,

- $\quad$ Class $\mathrm{C}$ can be regarded as tolerable insofar as an abuse of only $2^{\circ} \mathrm{C}$ is observed,

- Classes D and $\mathrm{E}$ gathering the most unfavourable observation regarding the preservation of food safety.

The belonging of one observation in one of these 6 classes is based on the mean temperature observed, either for the entire cold chain, or for the considered link of the cold chain.

\section{Quantitative approach}

Some statistics were carried out link by link of the cold chain. These elementary statistics (mean value and standard deviation and distribution function) concern the temperature and the residence time of the product in the different links. The difference between the total number of records (314) and the number of different identified links can be easily explained. For instance, the observation of 755 refrigerated transports is explained by the fact that each product undergoes an average of 2.5 transports (see below) and the observation of 251 household refrigerators can be explained by the fact that 93 consumer have unpacked their products before storing them in the refrigerator.

\section{RESULTS AND DISCUSSION}

The results presented below are based on the exploitation of 314 full records, representing more than 3800 days of record and more than 1.1 million data. Table 3 summarises the number of observations made in different links of the cold chain. 


\section{Description of a typical logistic circuit}

The sequencing of the thermal histories indicates that the majority $(46.7 \%)$ of the distribution circuits use 3 journeys between the factory and the retail, i.e. that they go trough 2 intermediates: warehouse and / or distribution platform. The direct delivery represents $9.3 \%$ of the observations, and some atypical distribution circuits (4 intermediaries and 5 transports) are noted.

The Table 2 summarises the results. A small calculation led to the result that a product underwent an average of 2.55 transports between the end of the production line and the retail.

\section{Quantitative approach.}

Figure 6 represents the result obtained for the "professional" part of the cold chain, i.e. storage, transport and retail. It clearly indicates a good professionalism of the upstream part of the cold chain. The temperature exceeding observed in some cases (13.6\% of the observation in class $\mathrm{C}$, and $0.6 \%$ in class $\mathrm{D}$ ) is related to the weakness of the retail link (see below).

Figure 7 confirms a real weakness of the links managed by the consumer: $67.7 \%$ of the observations are over the recommended conservation temperature and $20.2 \%$ of them dramatically exceed the recommended temperature. This observation confirms the results presented by [ 1 ], [ 3 ], [ 4] and many other authors.

Figure 8 describes more precisely the results obtained for the different links of the cold chain. It clearly indicates that some exceeding temperatures occur at retail level $(23.4 \%$ of the observed temperature in the display cabinets are in class $\mathrm{C}$, and $7.3 \%$ in the classes $\mathrm{D} \& \mathrm{E}$ ), and that the consumer has some difficulties to manage the temperature of his food, especially during the transport between retail and home.

All these qualitative results confirm the literature review. One of the most interesting aspects of the present work is to quantify these thermal histories, especially in terms of residence time of the products in the different links: the literature is indeed very poor in this domain, and this parameter, combined with the temperature, is indispensable to the evaluation of food safety.

\section{Quantitative approach.}

\section{Mean temperature in the different links}

Table 4 and Table 5 summarise the main statistics describing the observations. For the mean temperature level in the different links, a normal distribution law was retained, and classically, a gamma law was chosen to describe the variance of these observations.

Some variance analysis, combined with logical deductions sometimes allows one to gather the results observed for meat products and dairy products. For instance, there is no reason for the temperature in the household refrigerator to depend on the nature of the product, insofar as the consumer often arranges his products in a random way in his refrigerator. This report was confirmed by a variance analysis. 
The obtained results confirm the observation proposed by different authors, especially for the household refrigerator [ 1 ]. One can notice that for the transport, the warehouse and the display cabinet, the temperature is adjusted to the product's requirement. This fact indicates that the refrigerating equipment is adapted to the product it has to refrigerate, even if some cases of excessive temperature can be observed, especially in display cabinets.

It also appears that the distribution platform and the local cold rooms do not have specific uses depending on the product: these equipments can forward dairy products as well as meat products and posses only one temperature setting.

\section{Residence time of the products in the different links of the cold chain}

The Figure 9 and the Table 1 shows the observed mean residence time of the products in the different links of the cold chain. The weight of three links clearly appears: storage in warehouses, the display cabinet and the household refrigerator.

The transport link is quite short: 5.8 hours on average. But each product undergoes an average of 2.5 transports that explains that a product spends an average of 14.8 hours in trucks. Combined with an estimated speed of $65 \mathrm{~km} / \mathrm{h}$ on French roads, it can be estimated that a product travels $950 / 1000 \mathrm{~km}$ between the end of the production line and the consumer's plate... In connection with the size of the country, this value is consistent with an American study [ 5 ] that indicates an average covered distance of $2100 \mathrm{~km}$ in the US.

The residence time in warehouses greatly depends on the product. It appears to be particularly long for the prepared meat products which have a long lifespan (35 up to 42 days for some studied products), and evidently shorter for sensible products such as packed meat (1 day).

The residence time in the display cabinet appears to be as long as the one in the household refrigerator (3-4 days). In connexion with the report that these two links are the weakest this fact is of prime importance regarding food safety.

The duration of the domestic transport between retail and the consumer's home has a typical value of 1 hour. This quite short duration leads to think that the impact of this link on food safety should be less important than expected, which remains to be experimentally checked. Nevertheless, its impact on the quality of the product should remain non negligible.

Globally, one can say that a refrigerated product spends the $2 / 3$ of its life in a environment managed by "professionals" of the cold chain.

\section{CONCLUSION}

The results of this study confirm the classical feeling one can have on the refrigerated food cold chain:

- The first links appears to be very efficient, especially refrigerated transport,

- The retail level appears to be one of the weakest links of the professional part of the cold chain as some temperature abuses may be observed,

- The consumer has some difficulty to manage his/her own cold chain.

One of the originalities of this study is to quantify the couple residence time / temperature in each link of the cold chain. This coupling, based on an elementary integration 
$\int$ temperature $^{2} d t$ as proposed by [ 7 ] indicates that, compared to the maximum integrated value determined by the use-by date determination:

- The gathering of transport / warehouse / distribution platform weighs 4 to 5 time less than the retail,

- the retail and the household refrigerator have a weight of the same magnitude,

- the domestic transport weighs 15 to 25 times less than all the other parts of the cold chain.

Apart from some excessive cases in which the totality of the time / temperature capital was consumed, the observation indicates that, on average, the refrigerated food products are conserved in good conditions, especially in transport, warehouses and distribution platforms. The continuation of the present work will be to use the data base coming out of this study to relate the physical parameters describing the cold chain with food safety issues by using adequate predictive microbiology models. These results are of high interest for food manufacturers especially for the determination of use-by dates which are currently determined on empirical bases. From a research point of view, the obtained data base allows the setting and the validation of thermal behaviour models of food products developed at Cemagref. Coupled with microbiological predictive models, these behaviour models will determine an integrated approach of the chilled product's safety evaluation. 


\section{ACKNOWLEDGMENT}

This study was achieved by Cemagref on the request of the French Association of the Food Industries (ANIA), with the financial support of the French Agricultural ministry (DGAl) and of two interprofessional associations (OFIVAL and ONILAIT).

\section{Résumé}

Dans le domaine de la sécurité alimentaire, le respect de la chaîne du froid est d'une importance primordiale et est attendue des consommateurs. Le présent article décrit une méthode originale de suivi intégral de la chaîne du froid de produits alimentaires réfrigérés de consommation courante destinés à la vente en libre service des super et hypermarchés en France. Cette méthode consiste en la dissimulation de mini-enregistreurs de température dans les produits en sortie de chaîne de fabrication et à envoyer ces produits instrumentés (et non distinguables des autres produits) dans les chaînes de distribution. En bout de chaîne du froid, le consommateur découvrant l'enregistreur dans le produit qu'il a acheté est invité à le retourner au laboratoire.

Trois types de produits on été choisi en fonction de leur température de conservation recommandée, de leurs formes et des circuits logistiques qu'ils sont susceptibles de suivre. 480 capteurs ont été envoyés. Un taux de retour de plus de $65 \%$ a permis l'observation de l'histoire thermique complète vécue par 314 produits alimentaires, représentant un cumul de plus de 3800 jours d'enregistrement.

Les résultats sont présentés sous forme qualitative (classes de respect / non respect des températures recommandées) et qualitative (moyenne des températures observées et temps de séjour des produits dans les différents maillons) sur l'ensemble de la chaîne du froid et maillon par maillon. Ces résultats indiquent que $3 / 4$ des produits sont conservés dans de bonnes à très bonnes conditions de température, et que $3 \%$ des observations dépassent de façon excessive les températures de conservation recommandées, en particulier sur les maillons aval de la chaîne du froid.

\section{BIBLIOGRAPHY}

[ 1 ] LAGUERRE O., DERENS E., PALAGOS B. - 2002. Study of domestic refrigerator temperature and analysis of factors affecting temperature: a French survey. International journal of refrigeration, vol. 25, $\mathrm{n}^{\circ} 5$, p. $653-659$

[ 2 ] FLYNN O. M., BLAIR I., McDOWEL D. -1992. The efficiency and consumer operation of domestic refrigerator. International journal of refrigeration, vol. 15, $\mathrm{n}^{\circ} 5$, p. $307-312$

[ 3 ] JAMES S. J., EVANS J. -1992. Consumer handling of chilled foods: temperature performances. International journal of refrigeration, vol. 15, n 5, p. $299-306$

[ 4 ] SERGELIDIS D., ABRAHIM A., SARIMEEI A., PANOULIS C., KARAIOANNOGLOU Pr., GENIGEORGIS C., -1997. Temperature distribution and prevalence of Listeria spp. in domestic, retail and industrial refrigerators in Greece. Inteernational journal of food microbiology. vol 34, pp 171-177.

[ 5] Annual congress of Transfrigoroute international, Oliva, 3-5 octobre 2002

[ 6 ] PALAGOS B., GUILPART J., DERENS E., PROSEN E. - 2002. Description de l'histoire thermique de produits alimentaires transportés sous régime de froid par analyse des autocorrélations. Rencontres AGORAL 2002 : Prévisions analyse et gestion du risque alimentaire, Nancy, 26-27 mars 2002. p. 261 267

[ 7 ] DERENS E., GUILPART J., PALAGOS B., PROSEN E. - 2004. Données chiffrées sur la chaîne du froid des produits réfrigérés. Revue générale du froid, $\mathrm{n}^{\circ}$ 1045, p. 27 - 32 


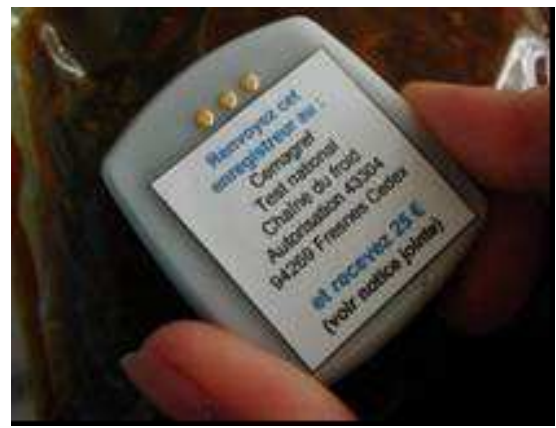

Figure 1 : Representation of the temperature recorder used in the present study

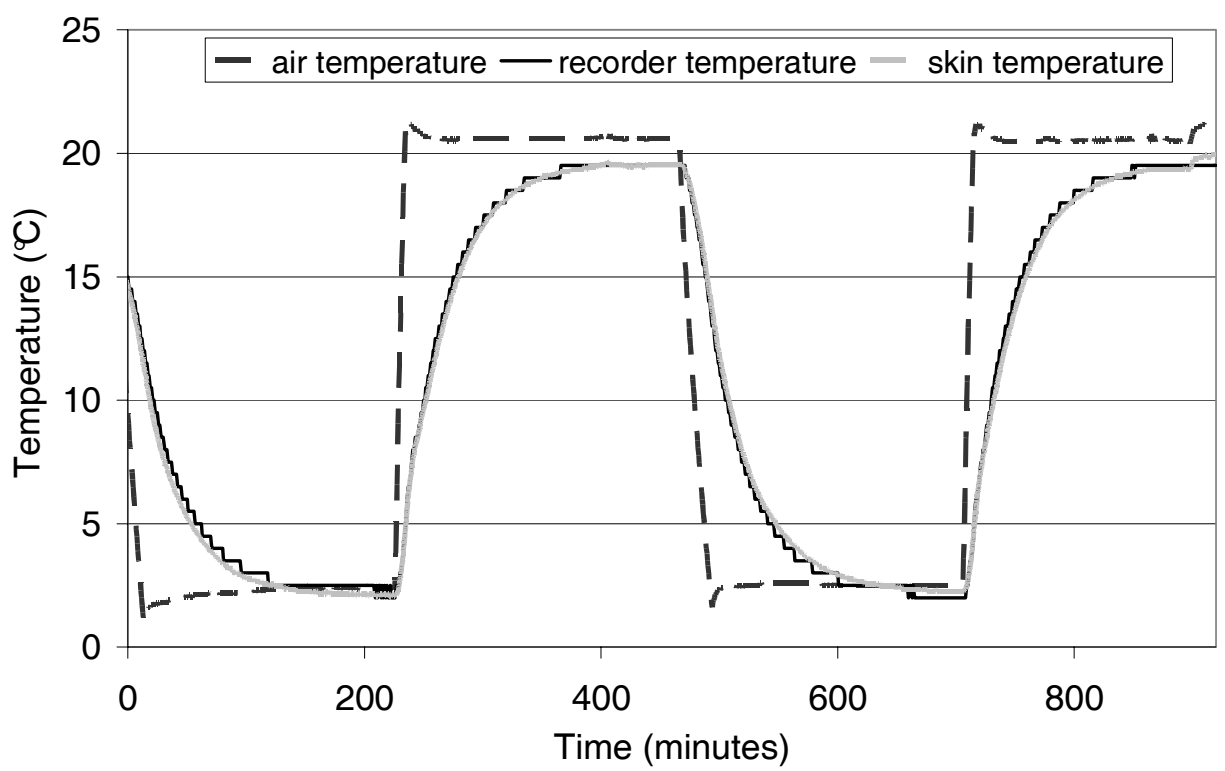

Figure 2: Recorded temperature in the case of a pot of a pot of yoghurt: the recorded temperature is $0.1^{\circ} \mathrm{C}$ close from the skin temperature of the product.

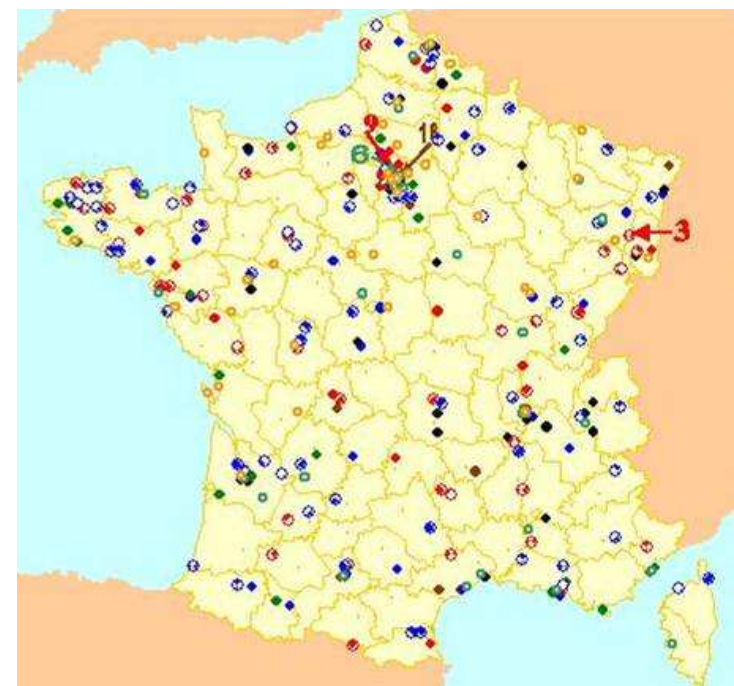

Figure 3 : Localisation of the return points of the recorders 


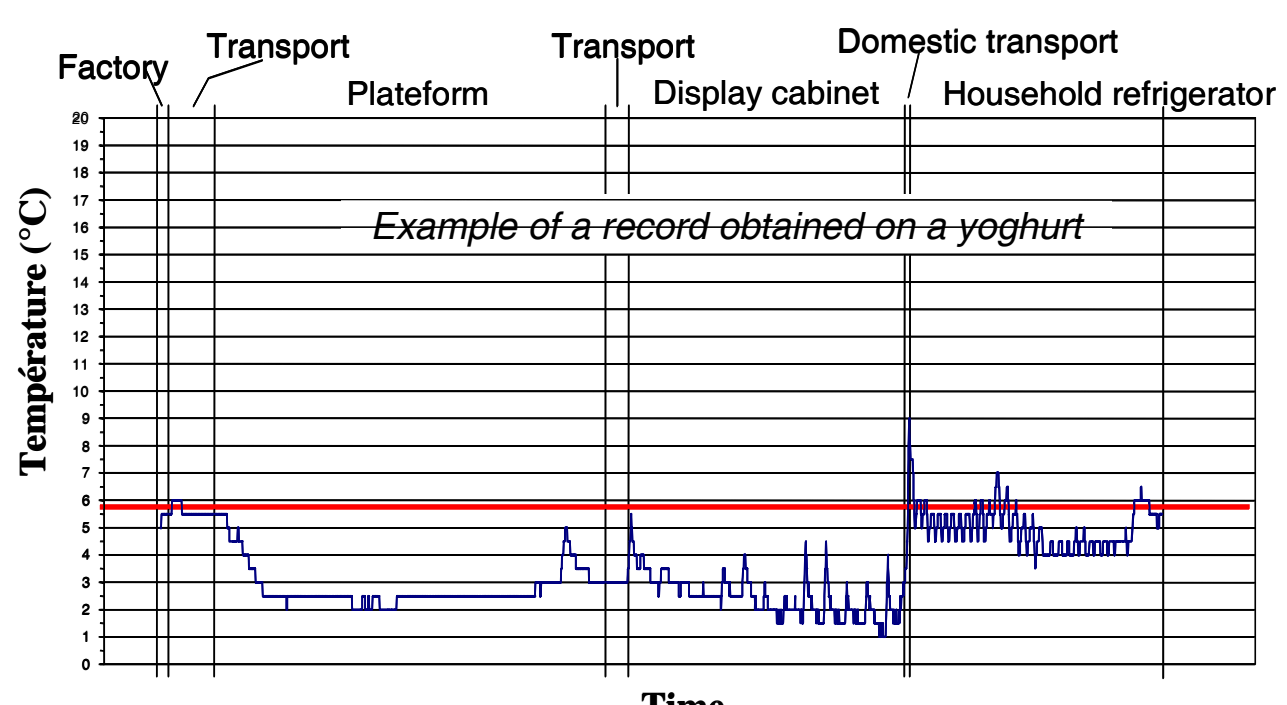

Time

Figure 4: Typical record obtained on a pot of yoghurt

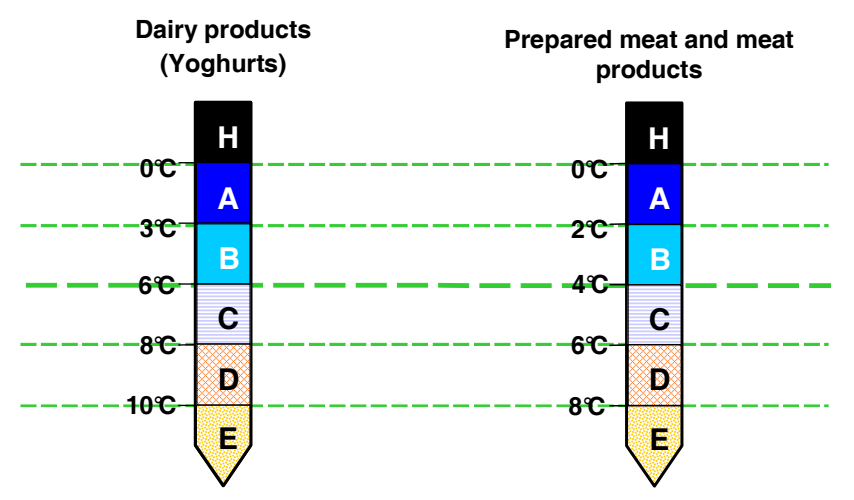

Figure 5: Definition of a reference scale

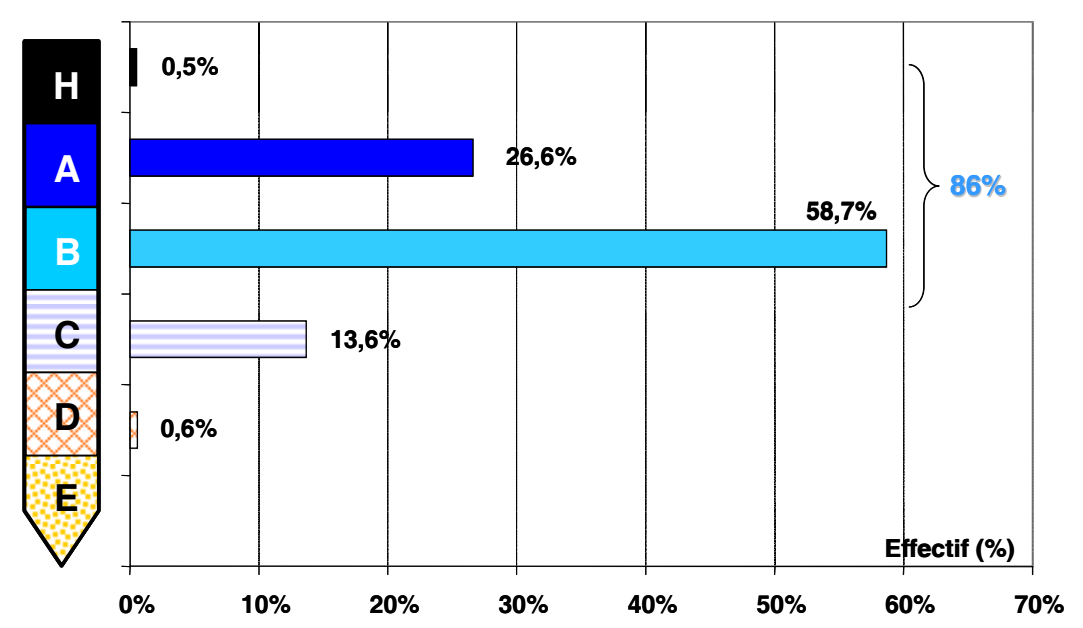

Figure 6: Evaluation of the professional part of the cold chain : $86 \%$ of the observations are good regarding the safety of food and $13.6 \%$ remain tolerable. 


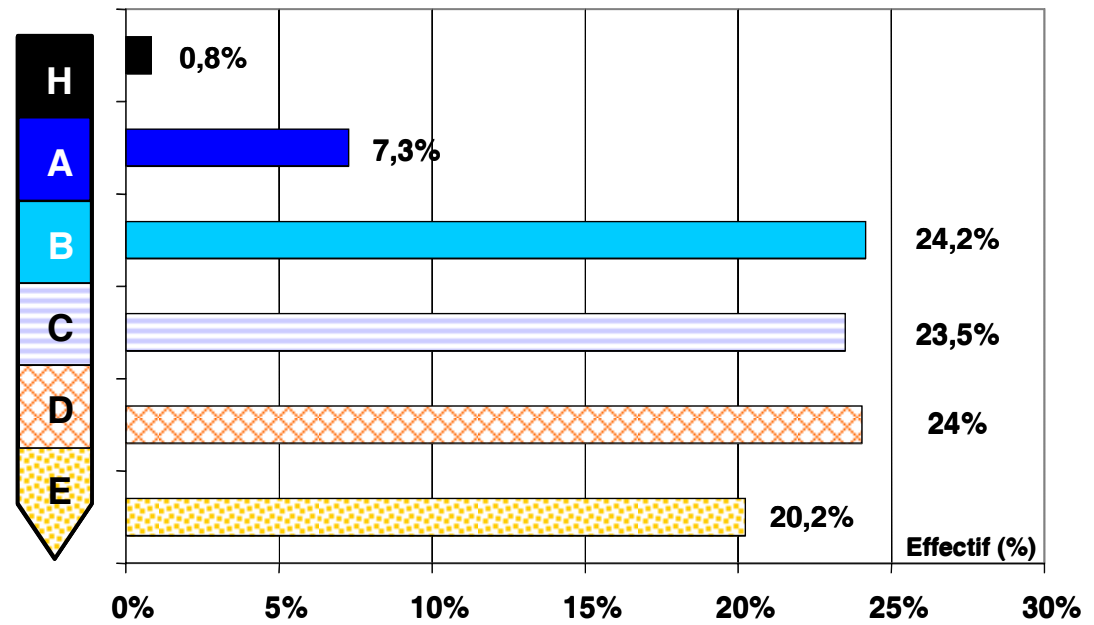

Figure 7: Evaluation of the cold chain managed by the consumer: $44.2 \%$ of the observations dramatically exceed the recommendation.

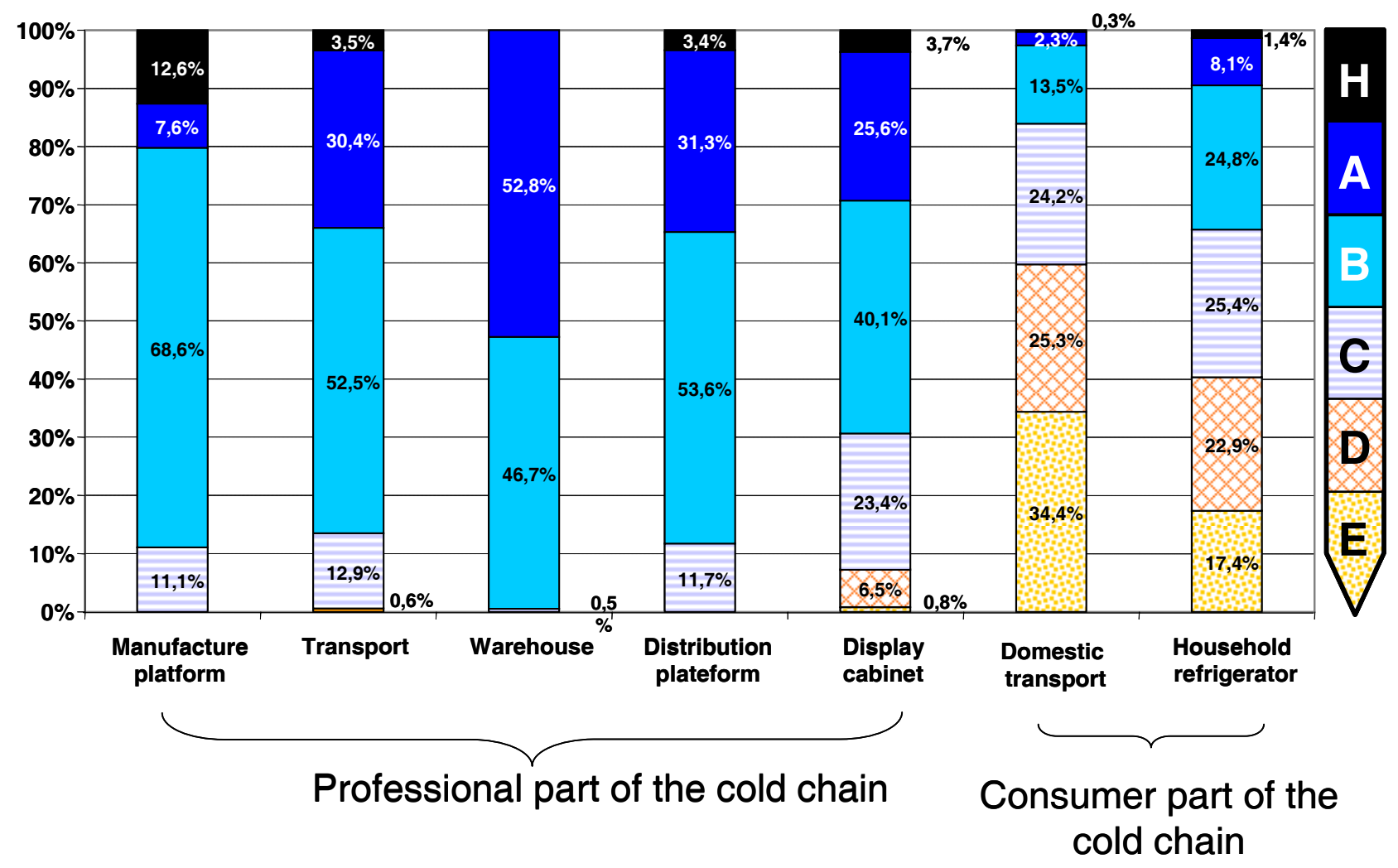

Figure 8: Performances of the different links of the cold chain. 


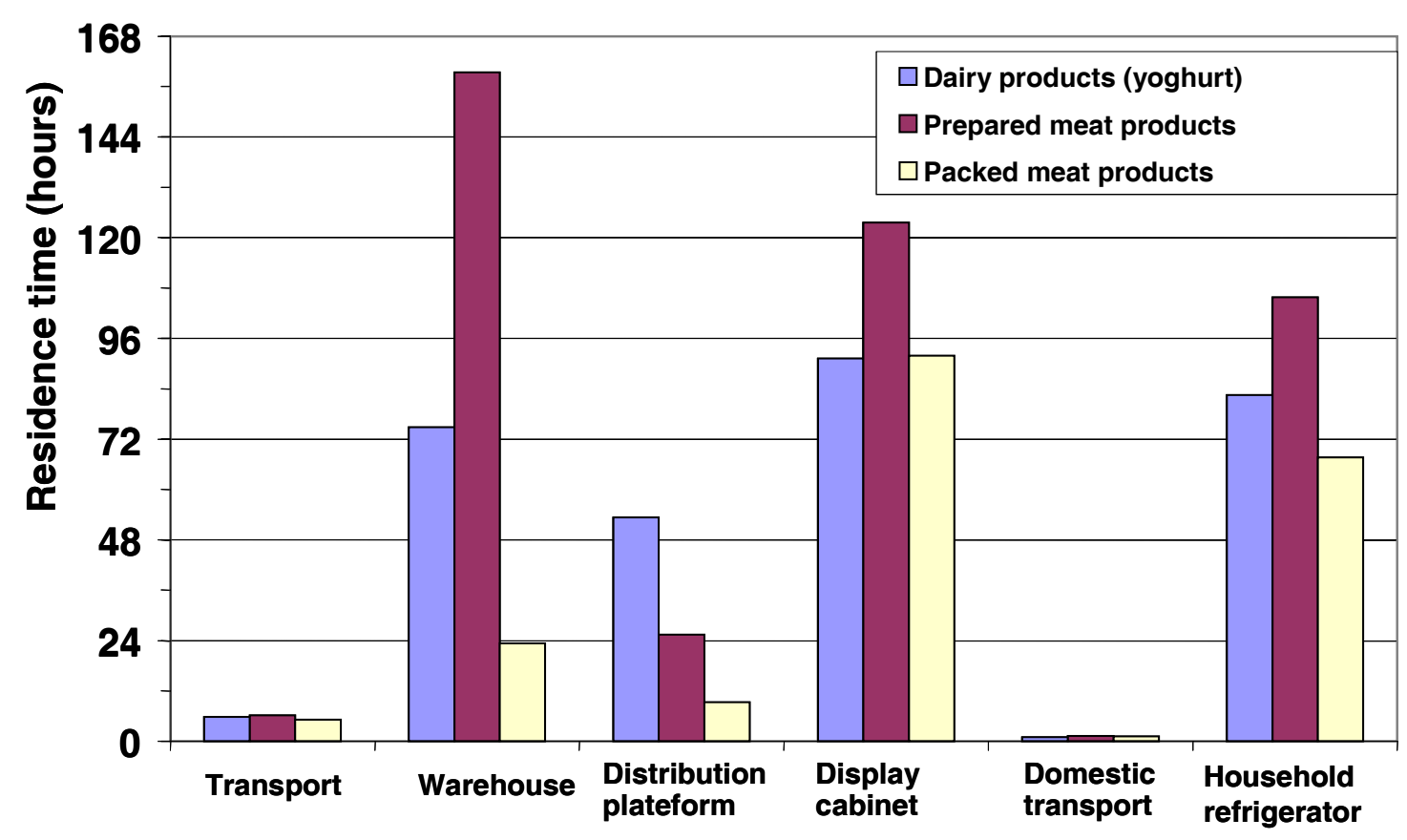

Figure 9: Residence time of different products in different links of the cold chain. 


\begin{tabular}{cccc}
\hline & $\begin{array}{c}\text { Number of send } \\
\text { recorders }\end{array}$ & $\begin{array}{c}\text { Number of recovered } \\
\text { recorders }\end{array}$ & Return rate \\
\hline Yoghurts & 190 & 120 & $63 \%$ \\
\hline Prepared meat products & 200 & 128 & $64 \%$ \\
\hline Packed meat & 90 & 66 & $73 \%$ \\
\hline Total & $\mathbf{4 8 0}$ & $\mathbf{3 1 4}$ & $\mathbf{6 5 \%}$ \\
\hline
\end{tabular}

Table 1: Number of send / recovered temperature recorder vs studied product and return rate of the recorders.

\begin{tabular}{cc}
\hline Number intermediates & \% observed \\
\hline $\begin{array}{c}0 \\
\text { (direct delivery) }\end{array}$ & 9.3 \\
\hline 1 & 34.9 \\
\hline 2 & 46.7 \\
\hline 3 & 8.6 \\
\hline 4 & 0.5 \\
\hline Total & $\mathbf{1 0 0}$ \\
\hline
\end{tabular}

Table 2: Logistic circuits observed: $9.3 \%$ of them are direct delivery and $0.5 \%$ of them undergo 4 intermediates (ie they undergo 5 journeys)

\begin{tabular}{cc}
\hline & $\begin{array}{c}\text { Number of identified } \\
\text { links }\end{array}$ \\
\hline Manufacture platform & 301 \\
\hline Transport & 755 \\
\hline Warehouse & 113 \\
\hline Distribution paltform & 344 \\
\hline Display cabinet & 307 \\
\hline Domestic transport & 302 \\
\hline Household refrigerator & 251 \\
\hline
\end{tabular}

Table 3: Number of identified links of the cold chain 
Prepared meat and meat products

Dairy products (yoghurt)

\begin{tabular}{|c|c|c|}
\hline Transport & $\mathcal{N}(2.85,0.75)[7]$ & $\mathcal{N}(4.17,1.47)[8]$ \\
\hline Warehouse & $\mathcal{N}(2.3,0.75)[3.7]$ & $\mathcal{N}(3.72,0.98)[6.5]$ \\
\hline Distribution platform & \multicolumn{2}{|c|}{$\mathcal{N}^{\circ}(3.2,1.3)[6.7]$} \\
\hline Display cabinet & $\mathcal{N}(3.2,2.0)[10.2]$ & $\mathcal{N}(4.15,2.14)[9.8]$ \\
\hline Domestic transport & \multicolumn{2}{|c|}{$\mathcal{N}(7.8,3.1)[18.4]$} \\
\hline Household refrigerator & \multicolumn{2}{|c|}{$\mathcal{N}^{N}(5.9,2.9)[13.8]$} \\
\hline
\end{tabular}

Table 4: Distribution parameters (Normal law) for the observed temperature in the different links of the cold chain. [Between brackets: maximum observed temperature]

Prepared meat and meat products

\begin{tabular}{lcc}
\hline Transport & $\Gamma(0.79,3.27)$ & $\Gamma(0.59,2.29)$ \\
\hline Warehouse & $\Gamma(0.96,5.79)$ & $\Gamma(1.3,5.7)$ \\
\hline Distribution platform & & $\Gamma(0.7,2.2)$ \\
\hline Display cabinet & $\Gamma(1.5,0.8)$ & $\Gamma(1.0,0.75)$ \\
\hline Domestic transport & \multicolumn{3}{c}{$\Gamma(0.8,0.3)$} \\
\hline Household refrigerator & \multicolumn{3}{c}{$\Gamma(0.8,0.5)$} &
\end{tabular}

Table 5: Distribution parameters (Gamma law) for the variance of the observed temperature in the different links of the cold chain

\begin{tabular}{lccc} 
& $\begin{array}{c}\text { Prepared meat } \\
\text { products }\end{array}$ & Packed meat & $\begin{array}{c}\text { Dairy products } \\
\text { (yoghurt) }\end{array}$ \\
\hline Transport & $6 \mathrm{~h}[21 \mathrm{~h}]$ & $5 \mathrm{~h}[22 \mathrm{~h}]$ & $6 \mathrm{~h}[2 \mathrm{~d}]$ \\
\hline Warehouse & $6.5 \mathrm{~d}[12.5 \mathrm{~d}]$ & - & $3 \mathrm{~d}[8 \mathrm{~d}]$ \\
\hline Distribution platform & $1 \mathrm{~d}[7 \mathrm{~d}]$ & $9 \mathrm{~h}[4 \mathrm{~d}]$ & $2 \mathrm{~d}[10 \mathrm{~d}]$ \\
\hline Display cabinet & $5 \mathrm{~d}[18 \mathrm{~d}]$ & $4 \mathrm{~d}[13 \mathrm{~d}]$ & $4 \mathrm{~d}[21 \mathrm{~d}]$ \\
\hline Domestic transport & & $1 \mathrm{~h} 06[13 \mathrm{~h} \mathrm{20]}$ & \\
\hline Household refrigerator & $4 \mathrm{~d}[23 \mathrm{~d}]$ & $3 \mathrm{~d}[15 \mathrm{~d}]$ & $3 \mathrm{~d}[26 d]$
\end{tabular}

Table 6 : Average residence time of different products in different links of the cold chain in hour (h) or days (d). [Between brackets: maximum observed value] 